\title{
Maximum Power Point Tracking Approach Based on Temperature for PV Surface Using PSPICE Program
}

\author{
Harith M. Saeed Hamed ${ }^{*}$ and Zainab M. Kubba ${ }^{* *}$ \\ Department of Physics, College of Science, Al-Nahrain University, Baghdad- Iraq. \\ Corresponding author : harithalnoori1992@yahoo.com *, z.kubba@yahoo.com *
}

\begin{abstract}
This paper studies the effect of PV surface Temperature on PV panel output characteristics. Circuit simulator PSPICE is used to compose PV panel model at $75 \mathrm{~W}, 4.8 \mathrm{~A}$ and $21 \mathrm{~V}$. The behavior of PV model under varying conditions (solar insolation, temperature and PV panel surface temperature) is studied. The ABM feature of PSPICE is used to include the above parameters in PV PSPICE model and produced temperature dependent voltage. This voltage is converted to current with galvanic insulation by element Gploy with gain 0.8. This model defined as a hierarchal block in PSPICE library and could be called as individual source for any applications. The effect of PV surface temperature on its I-V curves specially the positions of the MPP, is used to keep track of the MPP. Therefore, DC-DC boost converter was used to achieve this purpose. Boost converter was raised a PV panel voltage from $17 \mathrm{~V}$ to $34 \mathrm{~V}$ (for all variation of $\mathrm{PV}$ surface temperature $280 \mathrm{~K}$ to $360 \mathrm{~K}$ ) also output current $4.4 \mathrm{~A}$ for switching frequency $10 \mathrm{kHz}$ are selected.
\end{abstract}

[DOI: 10.22401/ANJS.21.4.06]

Keyword: MPPT, surface temperature, Boost converter and PSPICE.

\section{Introduction}

A typical solar panel converts between $(15-20 \%)$ of the incident solar irradiance into electrical energy. The essential devices Maximum Power Point Trackers (MPPT) systems is employed to maximize the power flow from a photovoltaic module (or array) to a load. In most applications, the MPPT is composed by a DC-DC converter and interpose between the photovoltaic module and load. [1] The output power of a solar panel is a function of the temperature, the sunshine and the position of the panel. Several MPPT methods exist in order to maximize this output power and to fix its value, in steady state, at its high level [2]. The most common techniques for MPPT are the output current, voltage or both of them. Roberto F. Coelho used the PV module temperature as an input to determine the MPP as a new technique [3]. The development of an algorithm that employs temperature measurement is based on the fact that the output photovoltaic voltage is directly proportional to the temperature of the photovoltaic surface. This algorithm is achieved by the following steps:

1. The PV panel surface temperature and output voltage are measured by sensors.
2. Both sense values are set as input data for the tracking algorithm, whose output is the duty cycle of the DC-DC converter.

In this paper, the PV panel has been simulated within the PSPICE simulator. Temperature of Photovoltaic panel is measured to estimate its effect on the MPPT of a PV system. Details are also given to the method of recording the panel temperature and several techniques in order to create a new component PV in Orcad - PSPICE simulator library which will be called directly by their equivalent circuits.

\section{PV panel PSPICE model}

A photovoltaic module is mathematically modelled using a single diode equivalent circuit. The various parameters which influence the characteristic of a cell are classified as three parameters firstly environmental parameters as solar irradiance and temperature. Secondly internal parameters as ideality constant, energy band- gap and charge of electron and thirdly electrical parameters like open circuit voltage, short circuit current, series resistance, and shunt resistance [4].

A previous work will be a starting point to build a developed panel model with the help of 
PSPICE program. Therefore, the same model will be constructed first and solar radiation and surface temperature will be added as a variable to control the PV panel output.[5] Now it is possible to create the PV panel consist of 36 elementary cells in series as shown in Fig. (1). The value of Rs for whole model is the sum of the internal resistance of all the cells.
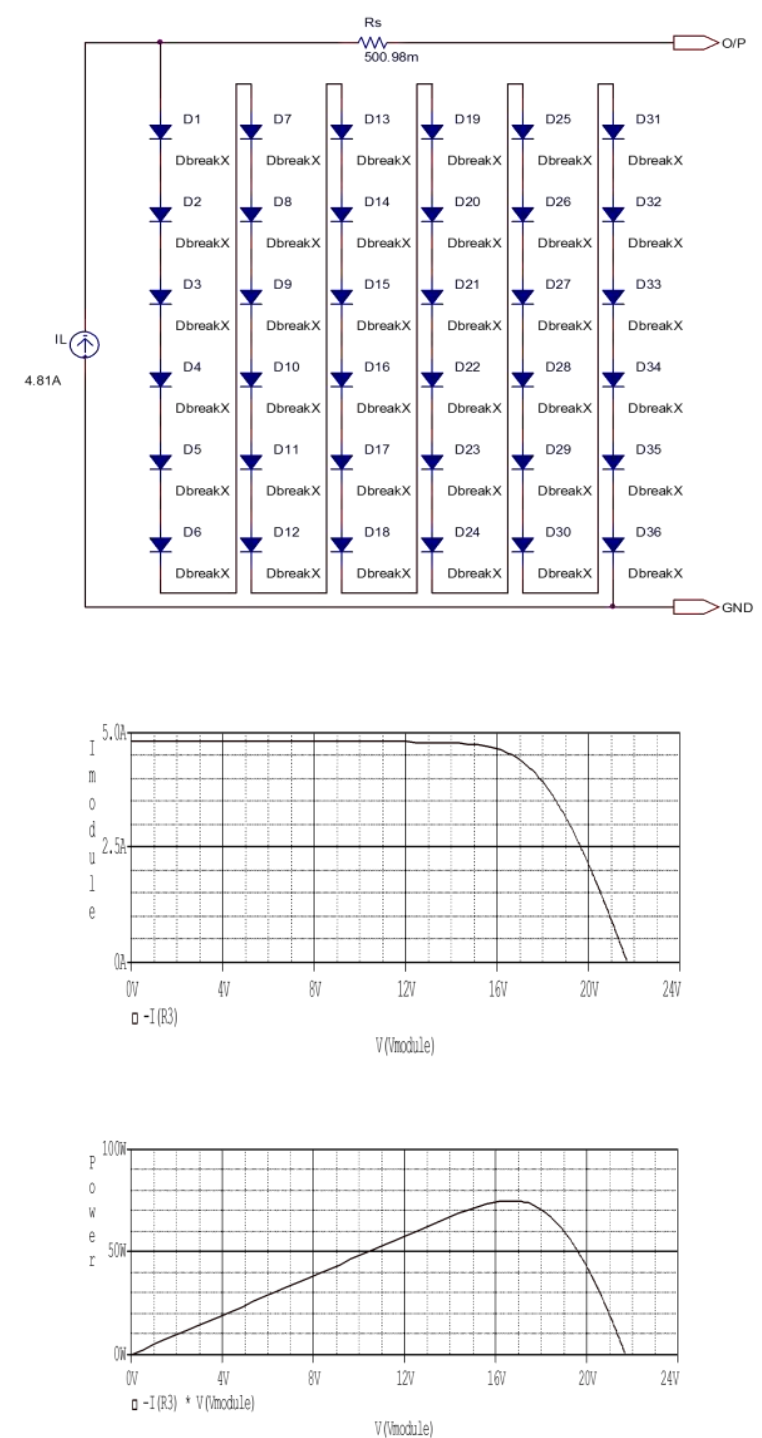

Fig.(1): Previous PSPICE PV panel model.
Temperature and solar radiation are the most important parameters affected the PV panel output. So they will be add to the previous model to improve it is behavior. This improvement will be helpful to verify different types of PV systems. To achieve this work the following equation was employed in the previous mathematical PV model as shown in Fig. (2). [6][7]

$\mathrm{I}_{\mathrm{PH}}=\left[\mathrm{I}_{\mathrm{SC}}+\mathrm{K}_{1}(\mathrm{~T}-298) *(\mathrm{Sol} / 1000)\right]$

Where:

$\mathrm{K}_{1}$ : short circuit current temperature coefficient equal $0.0017 \mathrm{~A} /{ }^{\circ} \mathrm{C}$.

$\mathrm{I}_{\mathrm{PH}}$ : represented photovoltaic current (A).

$\mathrm{T}$ : cell temperature ${ }^{\circ} \mathrm{C}$.

Sol: solar irradiance $\left(\mathrm{W} / \mathrm{m}^{2}\right)$.

$\mathrm{I}_{\mathrm{SC}}$ : short circuit current (A).

The ABM feature of PSPICE is used to include the above parameters in PSPICE model and produced temperature depending on voltage. This voltage converted to current with galvanic insulation by element Gpoly with gain (0.8). 


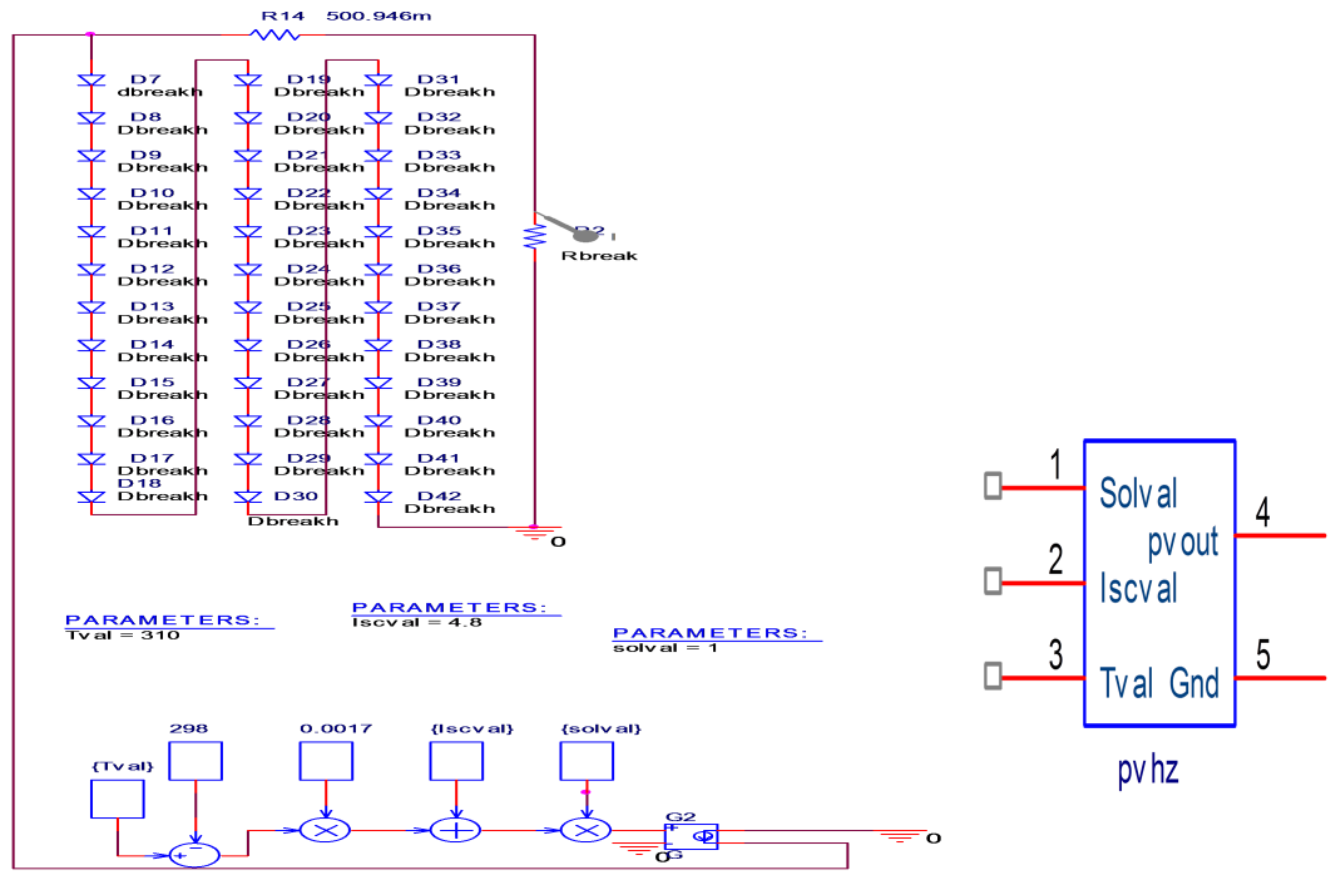

Fig.(2): The created PV panel as represented on Orcad-PSPICE.

Till now the circuit simulator PSPICE is used to compose PV panel model at $75 \mathrm{~W}$, $21.7 \mathrm{~V}$ open circuit voltage and $4.8 \mathrm{~A}$ short circuit current at $25^{\circ} \mathrm{C}$ with $1000 \mathrm{~W} / \mathrm{m}^{2}$. Fig. (3) shows the current-voltage curve and power - voltage curve at different temperature which is obtained from the DC analysis of the PV model. The optimal load replaced by $R_{\text {break }}$ to obtain all value of I and V.
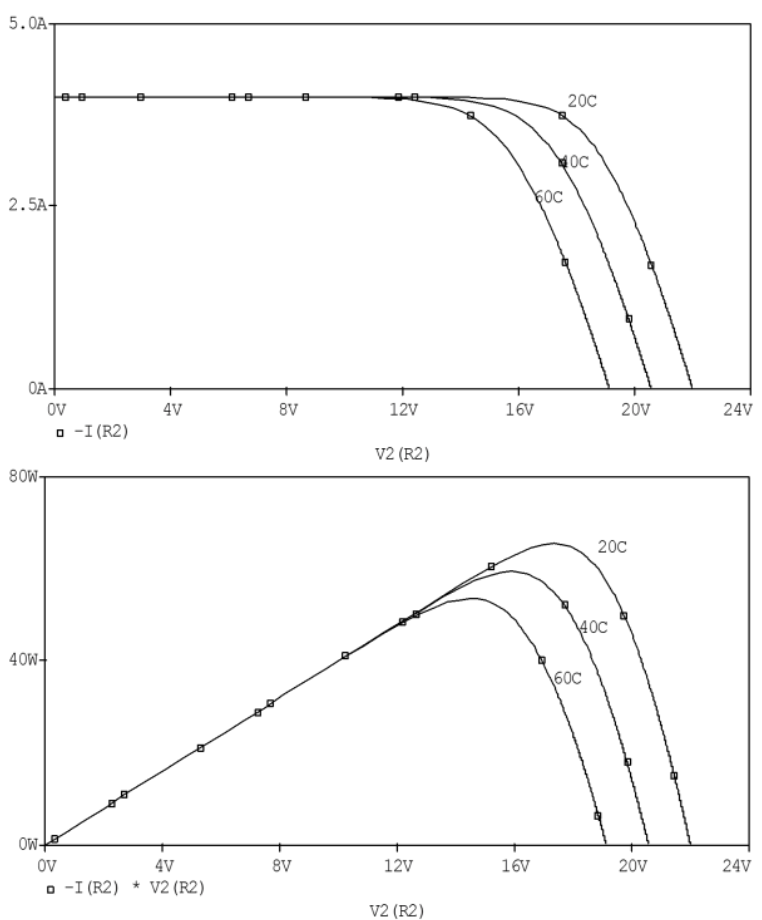

Fig.(3): (I-V) and (P-V) curves for PV panel at different temperature.
The following figures (4) and (5) illustrate the panel characteristics from this simulation at different short circuit current and irradiation respectively. These curves provide the PSPICE PV model, which could be used as a source of energy to the power circuit.
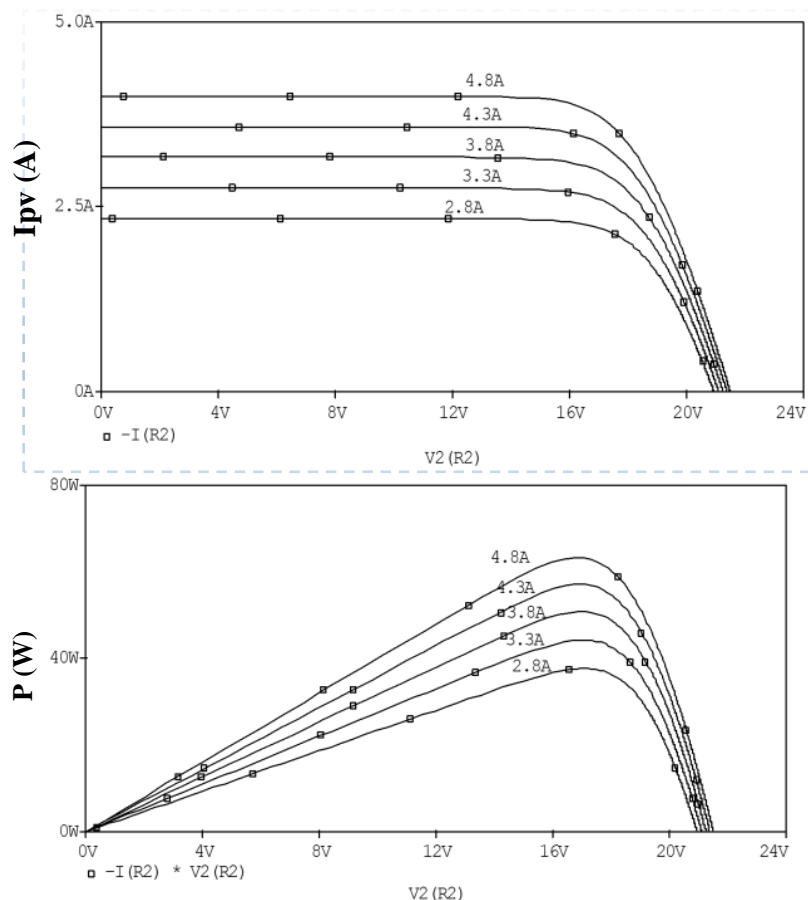

Fig. (4): (I-V) and (P-V) curves for PV panel at different short circuit current. 

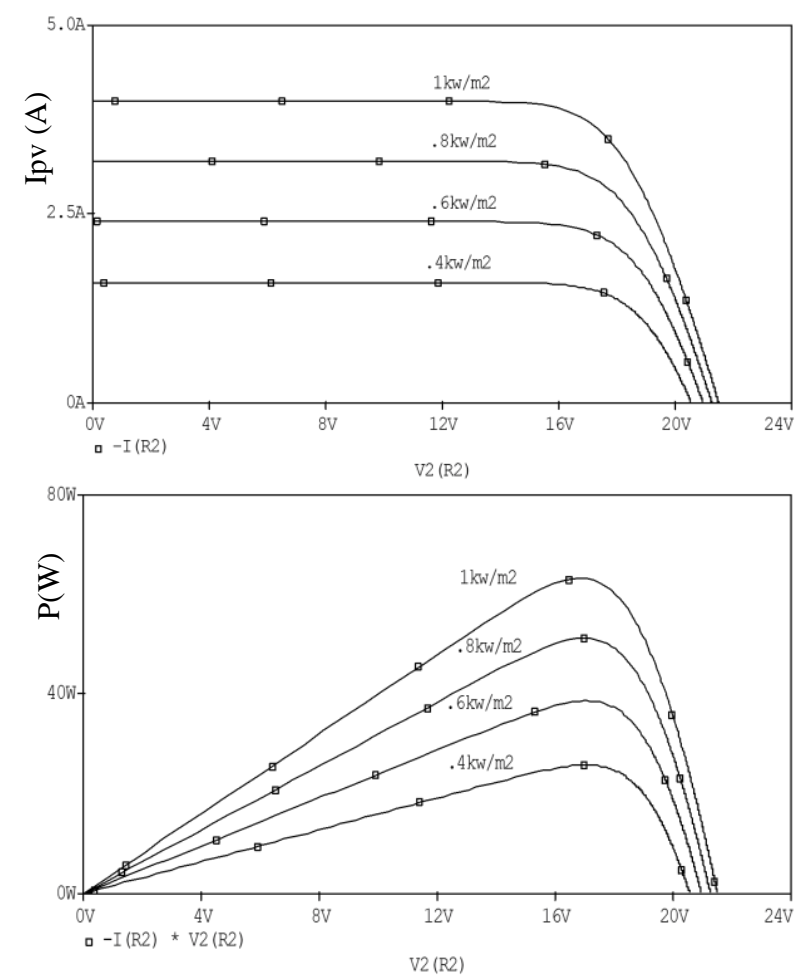

Fig.(5): (I-V) and (P-V) curves for PV panel at different irradiation.

The most important curves of the PV panel (I-V and P-V) for different surface temperature are shown in Fig.(6). This figure explains that the short circuit current have changed due to equation (1) where open circuit voltage is not.

The location of the maximum power point in the $(\mathrm{P}-\mathrm{V})$ panel is not known beforehand and always changed dynamically depending on irradiance, surface temperature and short circuit current as shown in the figures.
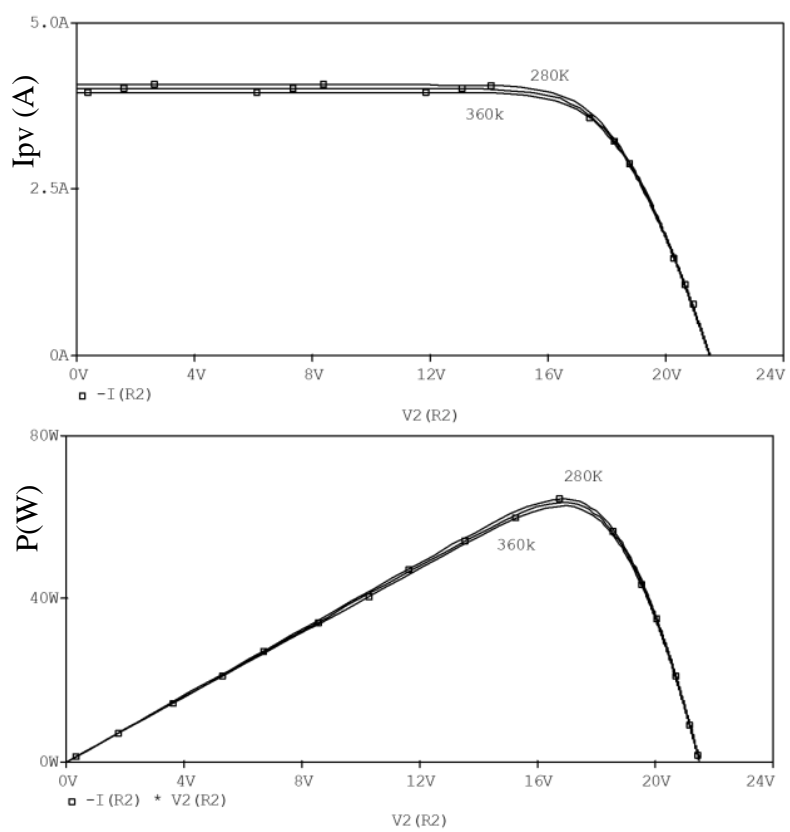

Fig.(6): (I-V) and (P-V) curves for PV panel at different surface temperature.

\section{Electrical Boost Converter}

After studying the effect of PV surface temperature on its $\mathrm{I}-\mathrm{V}$ curves specially the position of the MPP, this temperature will be used to keep track of the optimal voltage for the PV panels at the MPP. The Boost converter shown in Fig.(7) will raise a PV panel voltage from $(17 \mathrm{~V})$ to $(34 \mathrm{~V})$. Assuming $\mathrm{I}_{\mathrm{o}}=4.4 \mathrm{~A}$ and $\mathrm{f}_{\mathrm{S}}=10 \mathrm{KHz}$. [8][9].



Fig.(7): Electrical circuit of Boost Converter.

\section{Maximum power point tracking technique}

The MPPT is employed with boost converter in order to set the MPP as an operating point for large scale of irradiation and surface temperature. The PV voltage and PV surface temperature are the main factors in this work so, it is important to record these parameters. The PV voltage readings is recorded to compare it with the actual Maximum voltages of the I-V curves for assigned temperature in order to design a control signal for MOSFET gates of the converter. The measured PV surface temperature is represented as $\{\mathrm{val}\}$ in PSPICE program and the table part from analog behavioral modeling (ABM) library is used to convert the actual temperature to voltage as shown in the Fig. (8).

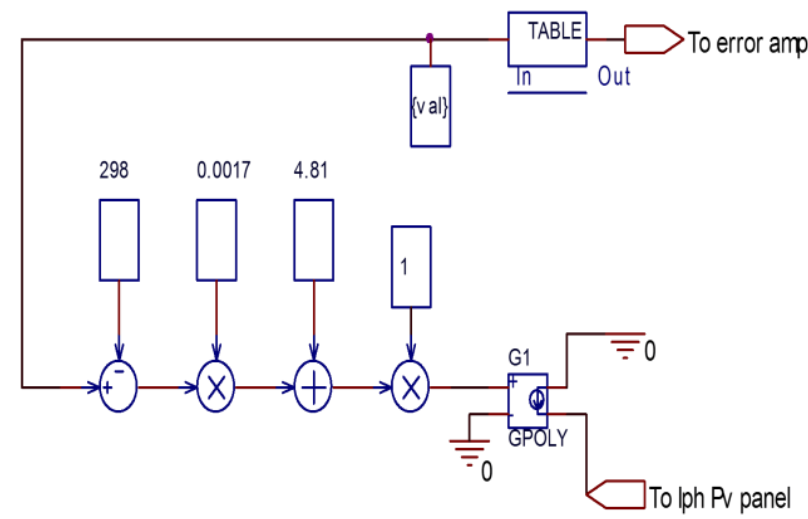

Fig.(8): Table part used to convert the actual temperature to voltage. 
The control signal "error signal" is achieved by comparing the output voltage for the PV panel with the voltage obtained from the output of the table by using Error amplifier as shown in Fig. (9).

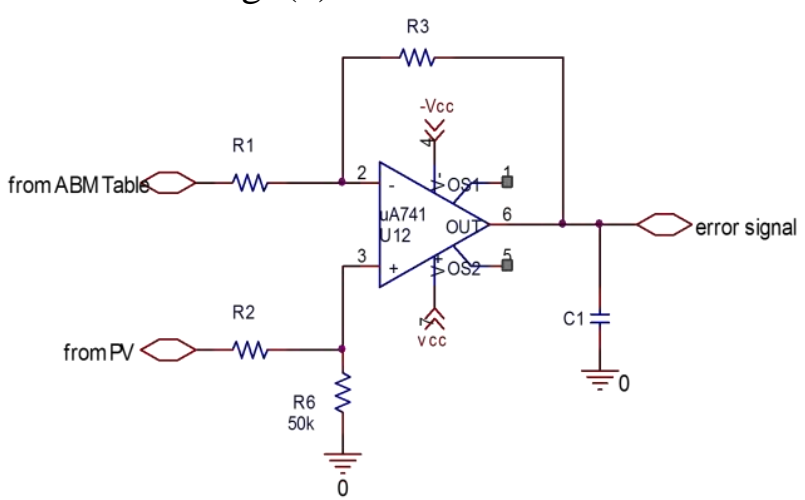

Fig.(9): The Error amplifier circuit.
PWM Signal and gate drive circuit

The error signal from Fig. (10) is applied to the control pin (no. 5 in 555 timer) which is tested as PWM. Transistor Q2 provides a square pulse of suitable voltage and current to the gate of converter transistor M5 as shown in Fig. (11). Finally, Fig (11) explained the total simulated circuit of PV system with temperature controlled at PSPICE.

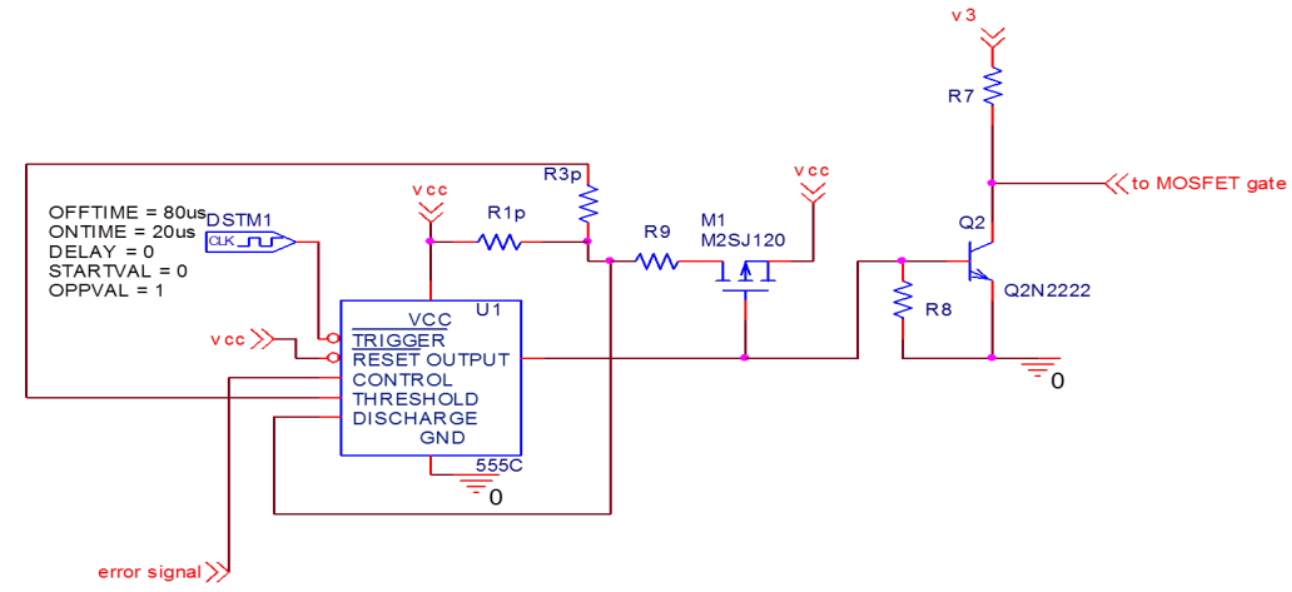

Fig.(10): PWM and gate drive circuit.

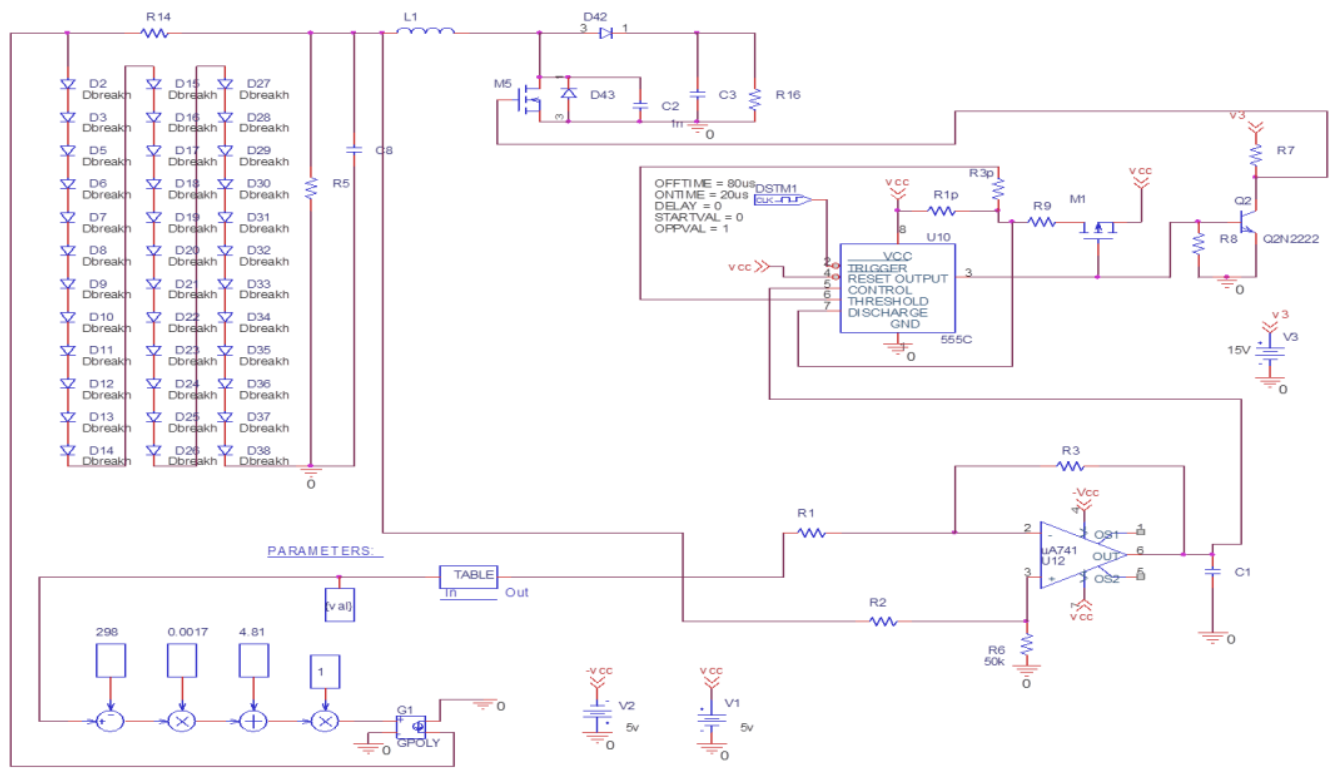

Fig.(11): The total simulated circuit of PV system with temperature controlled at PSPICE. 


\section{Results}

Fig.(12) and Fig.(13) represents the simulated $\mathrm{I}_{\mathrm{SC}}$ and a simulated PV panel output voltage for different surface temperature. The different duty cycle has been obtained from tasted circuit (555 timer) as seen in Fig.(14) below:

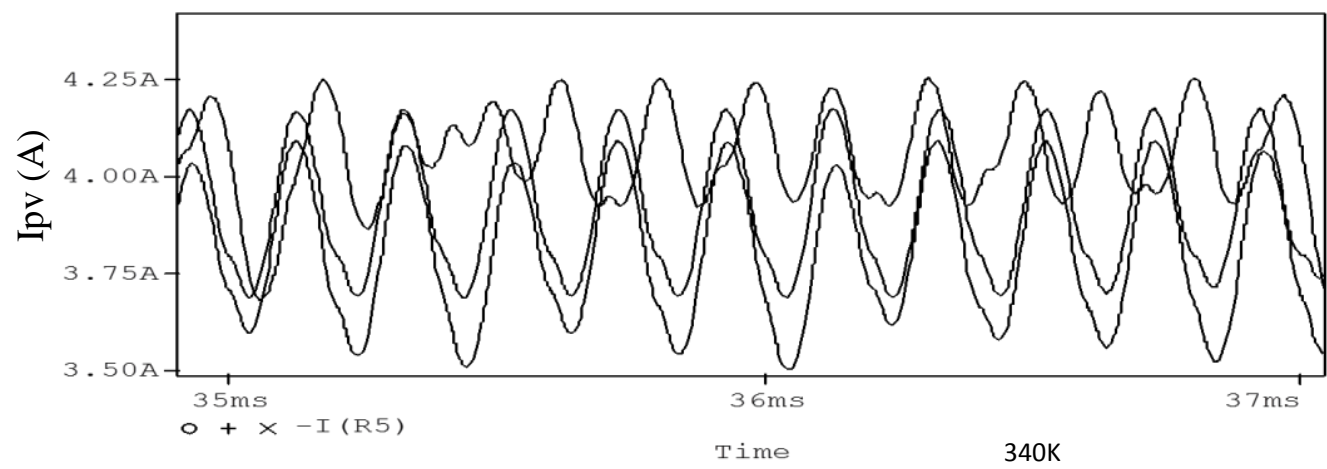

Fig.(12): Current from PV panel at different surface temperature.

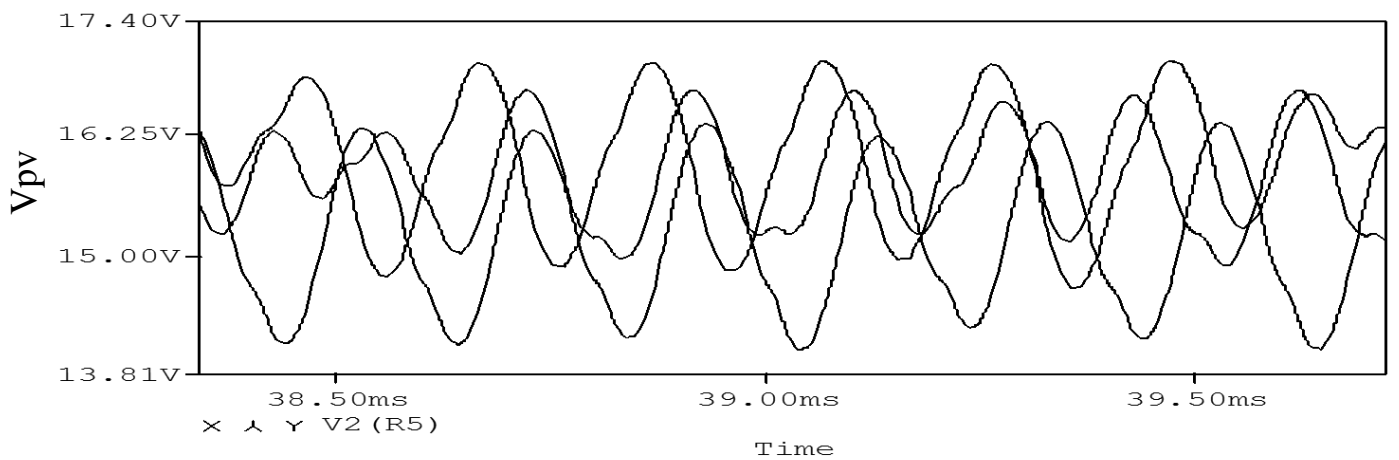

Fig.(13): voltage from PV panel at different surface temperature.

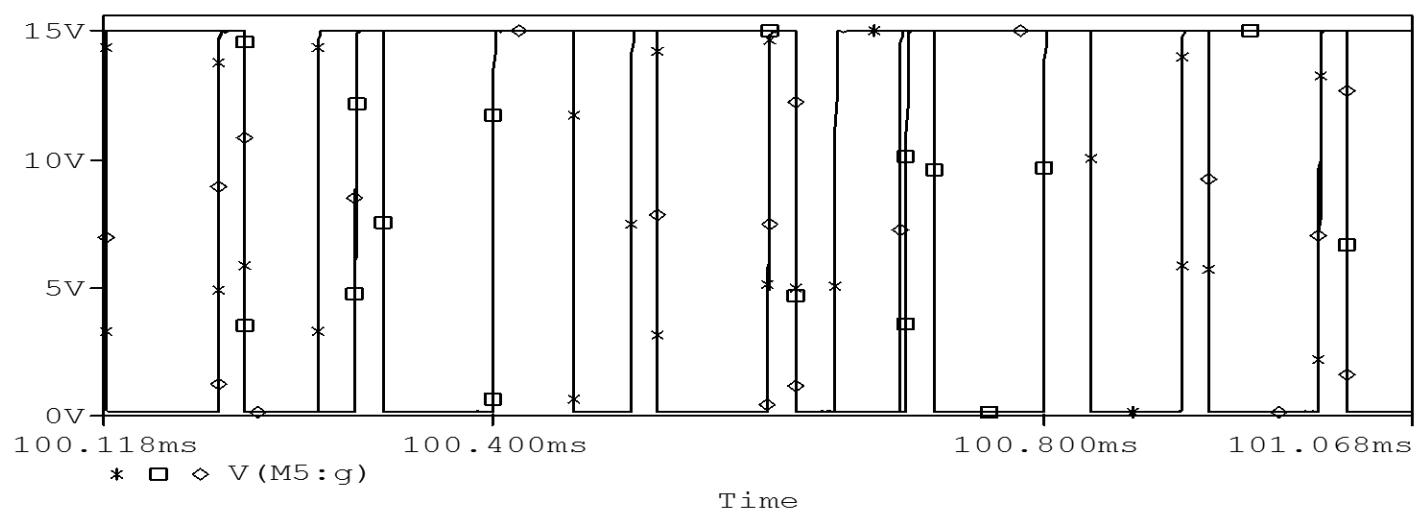

Fig.(14): PWM signal for different surface temperature from 555C.

Figures (15) and (16) show the output voltage and current from the designed boost converter at different PV surface panel temperature. The converter output voltage and current are constant for all surface temperature so the whole system achieve the required results. 


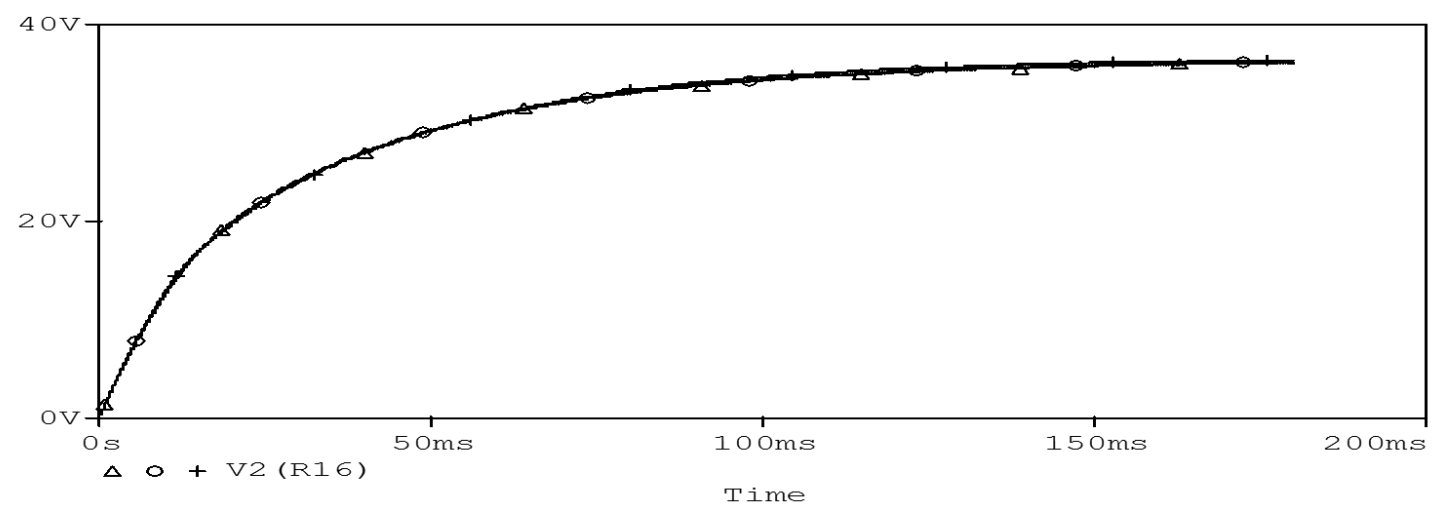

Fig.(15): Boost converter output voltage for different surface temperature.

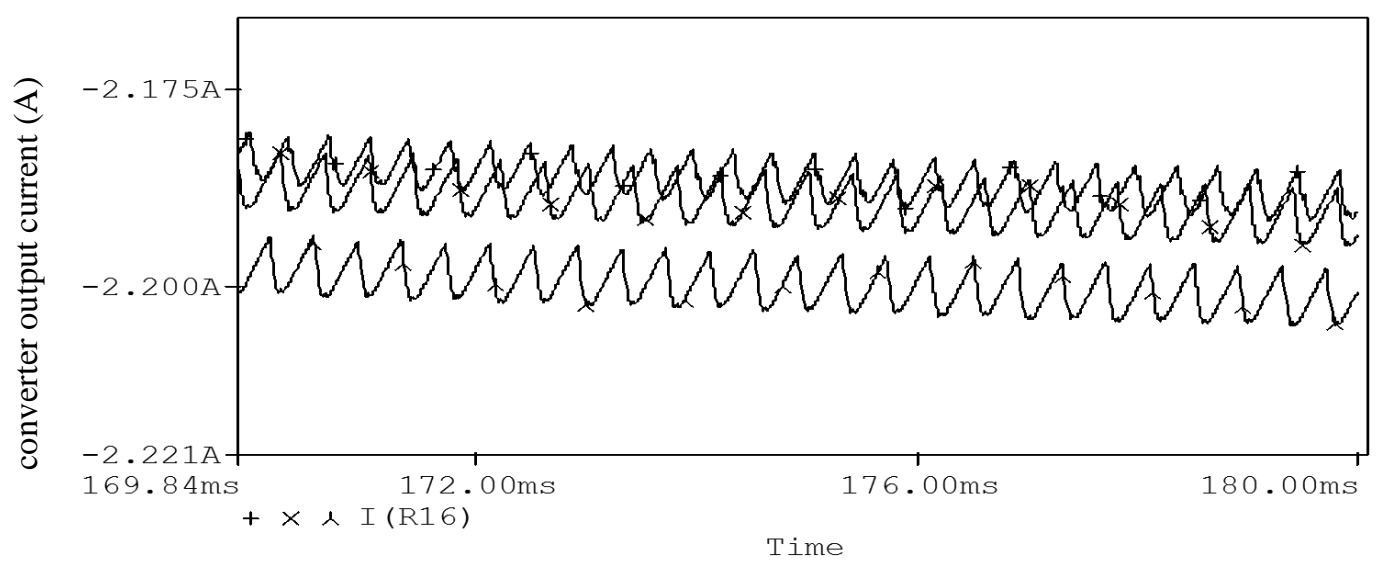

Fig.(16): Boost converter output current for different surface temperature.

\section{Conclusions}

From the developed pv model study, the following points could be concluded:

PV panel model defined as a hierarchical block in PSPICE library so, it could be called directly from PSPICE library as special source and use it for most PV systems applications. In all MPPT techniques a PV voltage and current should be measured, but for temperature technique just sensing the surface temperature. For this reason, this technique is used because it's easy and economical.

\section{References}

[1] Zainab Kubba, K. Al-Shara and EAlshakarchi "Computer aided design and implementation of converter circuit applied for Photovoltaic system" Journal of engineering, 4 (4), December 2008.

[2] Dr. Anil S. Hiwale, Mugdha V. Patil and Hemangi Vinchurkar "An Efficient MPPT Solar Charge Controller" International Journal of Advanced Research in Electrical, Electronics and Instrumentation Engineering" 3(7), July 2014.
[3] Roberto F. Coelho, Filipe M. Concer and Denizar C. Martins "A MPPT Approach Based on Temperature Measurements Applied in PV Systems" ICSET, Kandy, Srilanka, 2010.

[4] Savitha P B, Shashikala M S and Puttabuddhi K L "Modelling of Photovoltaic Cell/Module under Environmental Disturbances using MATLAB/Simulink" International Journal of Engineering Trends and Technology (IJETT), 9(1), 2014.

[5] Zainab M. Kubba and Zaid Samair "PSPICE model of the PV panel" Journal of Al-Nahrain University, 12(3), September, 2009.

[6] R.K. Nema, Sativa Nema and Gayatri Agnihotri "Computer Simulation Based Study of Photovoltaic Cells/Modules and their Experimental Verification" International journal of recent trends in Engineering, 1(3), May 2009.

[7] N. Hamrouni, M. Jraidi and A. Cherif "solar radiation and ambient temperature effects on the performances of a PV 
pumping system" Revue des energies renouvelables 11 (1), 2008.

[8] Roberto F. Coelho "A Simplified Analysis of DC-DC Converters Applied as Maximum Power Point Tracker in Photovoltaic Systems" IEEE international symposium on power electronics for distributed generation system, Brazil, 2010.

[9] Dr. Anil S. Hiwale, Mugdha V. Patil and Hemangi Vinchurkar "An Efficient MPPT Solar Charge Controller" International Journal of Advanced research in Electrical, Electronics and Instrumentation Engineering" 3(7), July 2014. 